Original Research Article

\title{
Comparative study about knowledge, attitude and practice study of fixed dose combination among junior residents and interns of a tertiary care hospital
}

\author{
Rupa Arun Korde ${ }^{1}$, Radhika M. S. ${ }^{1}$, Priya Gandigawad ${ }^{1}$, Ravi Sori ${ }^{1}$, Amruth ${ }^{2 *}$
}

${ }^{1}$ Department of Pharmacology, SDM College of Medical Sciences and Hospital, SDM University, Dharwad, Karnataka, India ${ }^{2}$ Department of Neurology, Karnataka Institute of Medical Sciences, Hubli, Karnataka, India

Received: 20 June 2018 Accepted: 26 July 2018

*Correspondence to:

Dr. Amruth,

Email:drrupa2@yahoo.co.in

Copyright: (C) the author(s), publisher and licensee Medip Academy. This is an openaccess article distributed under the terms of the Creative Commons Attribution NonCommercial License, which permits unrestricted noncommercial use, distribution, and reproduction in any medium, provided the original work is properly cited.

\begin{abstract}
Background: Fixed Dose Combinations (FDCs) are defined by the World Health Organization (WHO) as combination of two or more active ingredients in a fixed ratio of doses. According to the FDA, "two or more drugs may be combined in a single dose when each component makes a contribution to the claimed effects, and the dosage of each component (i.e., amount, frequency, and duration) is such that the combination is safe and effective for significant patient population requiring such concurrent therapy. However, certain disadvantages like incompatible pharmacokinetics, inflexible dose ratio, increased toxicity and cost, contraindication of one component of the FDC decreased their utility. Adverse effect of any one component also limits their use. The aim of the study is to compare and evaluate the knowledge, attitude and practices about prescribing fixed dose combinations among junior resident doctors (JRs) and interns (INTs) at SDM College of Medical Sciences and Hospital Dharwad.

Methods: A cross-sectional study was carried out in 134 doctors using prevalidated 10 item questionnaire with details of participant's information followed by questions regarding knowledge, attitude and prescribing practice of fixed dose combinations was used as a tool, administrated to all the resident doctors and the collected data was analysed.

Results: Our study revealed that knowledge about FDCs was lacking in JRs and INTs. They were not able to point out the actual advantages and disadvantages of FDCs. Knowledge about rational/irrational, banned FDCs and availability of WHO EML was also lacking.

Conclusions: There is need to improve knowledge about rationality, essential medicine list, usage and banned FDCs in undergraduate medical students to promote the rational use of drugs.
\end{abstract}

Keywords: Adverse effect, Essential medicine list, FDCs, WHO

\section{INTRODUCTION}

Fixed Dose Combinations (FDCs) are defined by the World Health Organization (WHO) as combination of two or more active ingredients in a fixed ratio of doses. ${ }^{1}$ The term FDC is used commonly to mean a rational combination of active ingredients irrespective of their formulation or brand. The FDC may be administered as a single entity product contemporaneously or as a complete pharmaceutical product.
According to the FDA, "two or more drugs may be combined in a single dose when each component makes a contribution to the claimed effects, and the dosage of each component (i.e., amount, frequency, and duration) is such that the combination is safe and effective for significant patient population requiring such concurrent therapy". ${ }^{2}$ The FDC products are acceptable only when the dosage of each ingredient meets the requirement of a defined population and when the combination has a proven 
advantage over single compounds administered separately in therapeutic effect, safety, or compliance. ${ }^{3}$

The FDCs are reasonable only when provide clear benefits in terms of increasing the therapeutic efficacy, decreasing the number of adverse effect of drugs, advantage in pharmacokinetic parameters, better patient compliance, reducing the dose of individual drugs and frequency of administration and more importantly having the pharmacoeconomical advantage. However, certain disadvantages like incompatible pharmacokinetics, inflexible dose ratio, increased toxicity and cost, contraindication of one component of the FDC decreased their utility. Adverse effect of any one component also limits their use.

In last few years CDSCO has approved 303 FDCs. ${ }^{4}$ This number is large when compared to the Essential Medicines List (EML) of WHO and national list of essential medicine. ${ }^{5}$ As of now studies were mainly focusing on prescribing pattern of FDCs and their rationality. ${ }^{6,7}$ Rationality status of many fixed dose combinations are marketed in India is not clear. ${ }^{8}$

There is much need to emphasize on rational method in prescribing of FDCs among young doctors. A study of knowledge, attitude and practice is the most important method to assess the benefits and lacunae about a subject in the community, so that effective steps can be taken in that direction to improve the outcome. Poor knowledge, inappropriate, indiscriminate use of FDCs may lead to prescription of irrational FDCs which may lead to unsafe and ineffective treatment, increased cost and unnecessary exposure of drug and adverse drug reactions (ADR). Hence the knowledge about prescribing fixed dose combinations is becoming increasingly important for better health outcomes.

All teaching hospitals have a dual role to play in terms of educating medical students and providing health care facilities to the patients. Only few studies have been conducted about the knowledge, attitude and practising of FDC drugs among junior doctors. Resident doctors and interns are primarily involved in patient management at tertiary care teaching hospitals, so their awareness about prescribing medicines is of prime importance for the treatment of patients. Thus, the present study was conducted.

Aim of the study was to compare and evaluate the knowledge, attitude and practices about prescribing fixed dose combinations among junior resident doctors (JRs) and interns (INTs) at SDM College of Medical Sciences and Hospital Dharwad.

\section{METHODS}

Descriptive study was carried out at Department of Pharmacology, SDM College of medical Sciences and
Hospital. Ethical approval was taken from the Institutional Ethics Committee prior to study.

The inclusion criteria was enrolment of junior residents and interns posted in various departments like medicine, surgery, paediatrics, obstetrics and gynaecology, skin and venereal diseases as well as the psychiatry departments and the exclusion criteria was senior residents, undergraduate students and Post graduate students and those who refused to give written consent were excluded from the study.

The study was conducted for duration of one month from August 2016 to September2016 and the study population was based on the inclusion criteria.

A total of 134 doctors 71 junior residents and 63 interns were participated in the survey. The participants were briefed about the nature and purpose of the study before subjecting to the questionnaire. Each participant was allotted 20 minutes for the completion of the study. Written informed consent was obtained from each participant. Informed consent was voluntary and freely given. A cross-sectional study was carried out using prevalidated 10 item questionnaire with details of participant's information followed by questions regarding knowledge, attitude and prescribing practice of fixed dose combinations was used as a tool, administrated to all the resident doctors.

\section{Statistical analysis}

The collected data was pooled and expressed as counts and percentages by statistical analysis which explores each variable in a data set separately. The results were analyzed by One way ANOVA followed by post hoc test using SPSS Software version 20 for windows. The results expressed are in mean $+/$ - standard deviation mean.

\section{RESULTS}

Among 134 doctors participated in the study, 71 were junior residents and 63 interns. The study was conducted to assess the information about the knowledge, attitudes and the practices of rational FDCs.

Survey results revealed that the knowledge of FDC among doctors. 33 (46.47\%) JRs and 46 (73.01\%) INTs had knowledge score of $70 \%$ and above which indicates that they were of the concept of FDC.

\section{Table 1: Mean score of knowledge and attitude} about FDC.

\begin{tabular}{|lll|}
\hline Score & Mean (SD) JRs & Mean (SD) INTs \\
\hline Knowledge & $4.45(0.92)$ & $4.96(0.82)$ \\
\hline Attitude & $1.91(0.96)$ & $1.87(0.83)$ \\
\hline
\end{tabular}


The assessment of questionnaire based on attitude regarding FDC shows that $23(32.39 \%)$ JRs and 18 $(28.57 \%)$ INTs had attitude score of $25 \%$. The attitude score was less compared to the knowledge score of JRs and INTs.

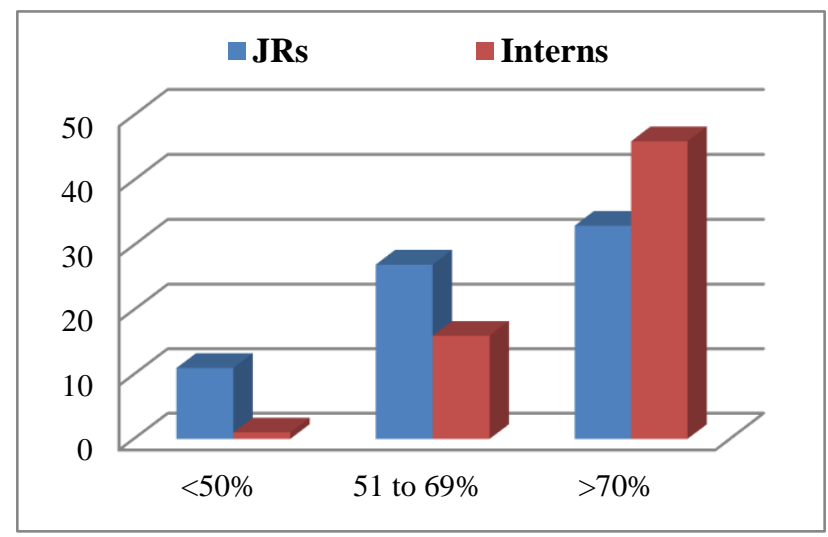

Figure 1: Knowledge scores of JRs and INTs.

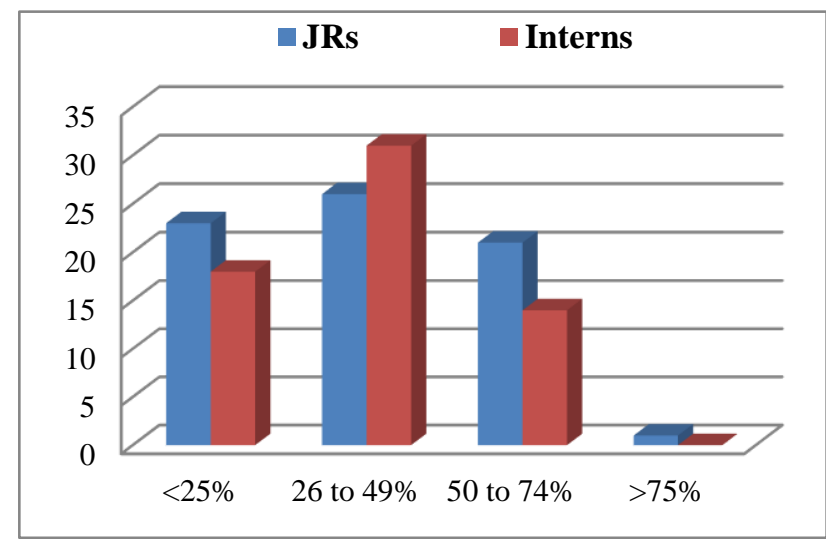

Figure 2: Attitude scores of JRs and INTs.

About 50 JRs and 46 INTs say that their under graduate knowledge of FDC is not sufficient for prescribing rational FDC which clearly states that, there is lack of orientation during their under graduate teaching regarding the FDC knowledge like their advantages and disadvantages, what are rational and irrational FDCs and the need of prescribing rational FDCs. Among 134 doctors only 17 JRs and 36 INTs have the idea that WHO decides whether the FDC drugs are rational or irrational.

\section{Table 2: Percentage of UG knowledge and WHO} criteria of deciding FDC.

\begin{tabular}{|ll|}
\hline UG knowledge & FDC- rational / irrational \\
\hline JRs - 50 (70.87\%) & JRs - 17 (23.94\%) \\
\hline INTs - 46(73.01\%) & INTs - 36 (57.14\%) \\
\hline
\end{tabular}

About 35 JRs and 49 INTs say that they have not seen any FDC related ADRs and only $35 \mathrm{JRs}$ and 41 INTs named FDC been prescribed or have seen being prescribed by specialists in the OPD. The above results indicate that the prescription of FDCs in the OPD is very less.

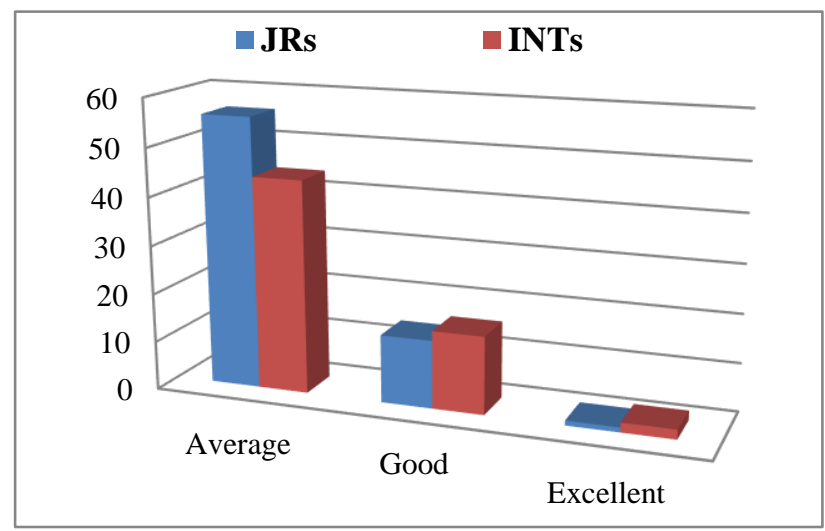

Figure 3: Undergraduate knowledge of FDC.

Table 3: Percentage of FDC related ADRs and FDC prescription in OPD.

\begin{tabular}{|ll|}
\hline FDC - ADRs & FDC- Prescription \\
\hline JRs - 35 (49.29\%) & JRs - 35 (49.29\%) \\
\hline INTs - 49 (77.77\%) & INTs - 41 (65.07\%) \\
\hline
\end{tabular}

Among 134 doctors 106 doctors mentioned that the FDCs prevent the development of drug resistance. Results shows that the most commonly prescribed FDC drug was Amoxicillin with Clavulanic acid known to the JRs and INTs. Knowledge about the availability of the WHO Essential Medicine List was lacking in JRs and INTs. 62 JRs and 58 INTs mentioned that antimicrobial drugs were most commonly prescribed group of FDC in the hospital. Among antimicrobials amoxicillin-clavulanic acid combination was the most commonly prescribed rational FDC in the OPD.

\section{DISCUSSION}

The knowledge possessed by a community is indicative of their understanding of the given subject. Attitude refers to their feelings towards this subject, as well as any preconceived ideas that they may have towards it. Practice refers to the ways in which they demonstrate their knowledge and attitude through their actions. ${ }^{9}$ The prescription of FDCs in clinical practice is notably increasing as there are number of advantages associated with the use of FDCs. But the inappropriate and indiscriminate use of FDCs due to poor knowledge may lead to irrational prescription. ${ }^{10}$ Irrational prescribing of FDCs lead to increased risk of adverse drug reactions, higher treatment cost, emergence of resistant organisms and for some time, treatment failure. ${ }^{11,12}$

It was observed from the study that the FDC prevents the drug resistance mentioned by JRs and INTs. But, according to WHO guidelines, there are a number of other advantages like decreased chances of ADRs, enhanced drug effects, simplified management and handling of drug 
convenience of prescribing. 70\% JRs and 73\% INTs states that their undergraduate level knowledge is insufficient for understanding and prescribing FDC drugs. $49.29 \%$ of JRs and $65.07 \%$ of INTs states that they have seen the FDC drugs prescribed by physicians in the OPD.

Results shows that the most commonly prescribed FDC drug was Amoxicillin with Clavulanic acid known to the JRs and INTs. Knowledge about the availability of the WHO Essential Medicine List was lacking in JRs and INTs.

This study revealed that knowledge about FDCs was lacking in JRs and INTs. They were not able to point out the actual advantages and disadvantages of FDCs. Knowledge about rational/irrational, banned FDCs and availability of WHO EML was also lacking. Other factors responsible for lack of knowledge may be lack of awareness during undergraduate training, less number of CME's and workshops stressing the importance of rational use of medicine and prescription. According to our study the INTs have more knowledge about the FDCs when compared to the JRs and reason may be the INTs have been posted in different departments during their tenure whereas the JRs are posted in a single department of their speciality. The INTs preparation for Post graduate exams have helped them in gaining more knowledge about FDCs. As our study revealed that JRs knowledge about FDCs is less compared to INTs, so there should be more need of sensitizing the postgraduates regarding FDCs practises.

\section{CONCLUSION}

The wellbeing of patients lies in the hands of healthcare professionals, so it is very important to sensitize the JRs and INTs about the rational prescribing of FDCs, advantages and its disadvantages. It can be started from the undergraduate level and continued in the post graduate level also. The teaching and exposing the undergraduate and postgraduate students to various information like essential medicine list, list of banned FDCs, are quite necessary to promote rational use of drugs.

Funding: No funding sources Conflict of interest: None declared

Ethical approval: The study was approved by the Institutional Ethics Committee

\section{REFERENCES}

1. WHO Expert Committee on Specifications for Pharmaceutical Preparations: thirty-ninth report. (WHO technical report series; 929); 2005.
2. Sreedhar D, Subramanian G, Udupa N. Combination drugs: are they rational? Curr Sci. 2006;91:406.

3. World Health Organization. The use of essential drugs. WHO Technical Report Series 825. Geneva: World Health Organization; 1992.

4. Fixed dose combinations approved by DCGI (i) since 1961 till November 2014. Available at: http://www.cdsco.nic.in/writereaddata/FDC_approve d_dcgi (1)_2013. Pdf (Accessed 18 May 2014).

5. WHO Model List of Essential Medicines. Available at: http://www.who.int/medicines/ publications/essentialmedicines/18th_EML_Final_we b_8Jul13.pdf (accessed 28 December 2014).

6. National List of Essential Medicines of India; 2011. Available at: http://apps.who.int/ medicinedocs/documents/s18693en/s18693en.pdf (accessed 28 December 2014).

7. Kataria BC, Bhavsar VH, Donga BN. Contemplation on approved drugs in India from 1999 through 2011. Asian J Pharm Clin Res. 2012;5(3):25-9.

8. Devi M, Sriram S, Rajalingam B, Anthraper AR, Varghese RS, Phani V. Evaluation of the rationality of fixed dose combinations of cardiovascular drugs in a multispecialty tertiary care hospital in Coimbatore, TN, India. Hygeia JD. 2012;4(1):51-8.

9. Badran IG. Knowledge, attitude and practice the three pillars of excellence and wisdom: A place in the medical profession. Eastern Mediterranean Hea J. 1995; 1:8-16.

10. Sarkar C, Das B. Prescribing trends of fixed dose combinations in a tertiary care hospital in Nepal. J Inst Med. 2000;22:53-8.

11. Shewade D, Pradhan S. Auditing of prescriptions in a government teaching hospital and four retail medical stores in Pondicherry. Indian $\mathrm{J}$ Pharmacol. 1998;30:408-10.

12. Sreedhar D, Subramanian G, Udupa. N. Combination drugs: Are they rational? Curr Sci. 2006;91:24-5.

Cite this article as: Korde RA, Radhika MS,

Gandigawad P, Sori R, Amruth. Comparative study about knowledge, attitude and practice study of fixed dose combination among junior residents and interns of a tertiary care hospital. Int J Basic Clin Pharmacol 2018;7:1728-32. 
ANNEXURE I: QUESTIONNAIRE FOR KAP SURVEY ON FDC.

\begin{tabular}{|c|c|c|c|}
\hline Sr. No. & Questions & \multicolumn{2}{|c|}{ Options } \\
\hline 1. & What is Fixed Dose Combination? & $\begin{array}{l}\text { A) } \\
\text { B) }\end{array}$ & $\begin{array}{l}\text { Combination of two different drugs } \\
\text { Combination of same drugs }\end{array}$ \\
\hline 2. & $\begin{array}{l}\text { How do you grade you under graduate knowledge of } \\
\text { rational FDC? }\end{array}$ & A) & Average B) Good C) Excellent \\
\hline 3. & $\begin{array}{l}\text { Does the UG knowledge of FDC is sufficient for } \\
\text { prescribing rational FDC? }\end{array}$ & $\begin{array}{l}\text { A) } \\
\text { B) }\end{array}$ & $\begin{array}{l}\text { Yes } \\
\text { NO }\end{array}$ \\
\hline 4. & Who decides whether an FDC is rational or irrational? & $\begin{array}{l}\text { A) } \\
\text { B) } \\
\text { C) } \\
\text { B) }\end{array}$ & $\begin{array}{l}\text { WHO } \\
\text { US-FDA } \\
\text { American Medical Association } \\
\text { American-Pharmaceutical Association }\end{array}$ \\
\hline 5. & When was the latest essential drugs list released? & A) & 2005 B) 2003 C) 2002 D) 1977 \\
\hline 6. & Find one Rational FDC among the following? & $\begin{array}{l}\text { A. } \\
\text { B. } \\
\text { C. } \\
\text { D. }\end{array}$ & $\begin{array}{l}\text { Amoxicillin + Clavulanic acid } \\
\text { Amoxicillin + Cloxacillin } \\
\text { Ofloxacin + Orinidazole } \\
\text { Ciprofloxacin + Tinidazole }\end{array}$ \\
\hline 7. & Does rational FDC of Antibiotics prevents drug resistance? & $\begin{array}{l}\text { A) } \\
\text { B) }\end{array}$ & $\begin{array}{l}\text { Yes } \\
\text { NO }\end{array}$ \\
\hline 8. & Do you think FDC are always advantageous? & $\begin{array}{l}\text { A) } \\
\text { B) }\end{array}$ & $\begin{array}{l}\text { Yes } \\
\text { NO }\end{array}$ \\
\hline 9. & Have you seen any FDC related ADRs? If yes name them & & \\
\hline 10. & $\begin{array}{l}\text { Name some FDC which you have prescribed or have seen } \\
\text { being prescribed by specialists in the } \\
\text { OPD }\end{array}$ & & \\
\hline
\end{tabular}

